\title{
Robert W. Greene, Searching for presence. Yves Bonnefoy's writings on art
}

\section{Rosa Galli Pellegrini}

\section{Q OpenEdition}

1 Journals

\section{Edizione digitale}

URL: http://journals.openedition.org/studifrancesi/35237

DOI: 10.4000/studifrancesi.35237

ISSN: 2421-5856

\section{Editore}

Rosenberg \& Sellier

\section{Edizione cartacea}

Data di pubblicazione: 1 novembre 2005

Paginazione: 453

ISSN: 0039-2944

\section{Notizia bibliografica digitale}

Rosa Galli Pellegrini, «Robert W. Greene, Searching for presence. Yves Bonnefoy's writings on art», Studi Francesi [Online], 146 (XLIX | II) | 2005, online dal 30 novembre 2015, consultato il 18 avril 2021. URL: http://journals.openedition.org/studifrancesi/35237; DOI: https://doi.org/10.4000/studifrancesi. 35237

Questo documento è stato generato automaticamente il 18 avril 2021.

\section{(c) (1)}

Studi Francesi è distribuita con Licenza Creative Commons Attribuzione - Non commerciale - Non opere derivate 4.0 Internazionale. 
Robert W. Greene, Searching for presence. Yves Bonnefoy's writings on art

Rosa Galli Pellegrini 


\section{NOTIZIA}

ROBERT W. GREENE, Searching for presence. Yves Bonnefoy's writings on art, Amsterdam-New York, Rodopi ed., 2004, pp. 204.

1 Questo studio denso e attento sull'attività di Yves Bonnefoy come critico d'arte o, per meglio dire, l'analisi degli scritti di quest'autore sull'arte, costituisce un approccio nuovo e originale agli interessi del poeta/scrittore. L'impianto forse un po' didattico del volume non nuoce tuttavia alla ricchezza dell'informazione. La premessa storica, che costituisce la prima parte, si avvia da Baudelaire per soffermarsi sul concetto di Poésie Critique, e per passare, nella seconda parte, al contesto del ventesimo secolo. Viene passata così in rassegna la tradizione critica che parte da Apollinaire e Malraux, per giungere a Ponge et Char. Un capitolo a parte è riservato a Jouve, come maestro di Bonnefoy.

2 La parte terza entra nel vivo, passando alla lettura critica del pensiero dello scrittore in materia artistica: dagli scritti in difesa delle pitture gotiche e in esaltazione del barocco, alle opinioni su Giacometti, dal Quattrocento a Tiepolo, alla pittura del ventesimo secolo, alla relazione comparata tra Delacroix e Shakespeare. Si evince, da questa lettura, il forte impegno critico di Bonnefoy, il suo concetto nel «se» della "presenza» dell'Altro, la sua convinzione del valore dell'arte, una totalità di riflessioni che vengono lasciate dal poeta in eredità a Claude Esteban, come l'autore conclude nella quarta e ultima sezione del suo saggio.

3 Una ricca bibliografia e un utile elenco dei nomi completa il pregevole saggio. 